\title{
Case report: Inferior vena-cava right atrial anastomotic stenosis after bicaval orthotopic heart transplantation
}

\author{
[Présentation de cas : sténose anastomotique auriculaire droite de la veine cave \\ inférieure à la suite d'une transplantation cardiaque orthotopique bicave]
}

Eric Jacobsohn FRCPC, ${ }^{*}$ Michael S. Avidan MBBCh FCA, ${ }^{*}$ Charles B. Hantler MD, $†$ Frank Rosemeier MD,$\dagger$

Charl J. De Wet MBChB*

Purpose: This case report describes the occurrence of acute postoperative liver and renal failure after bicaval orthotopic heart transplantation (OHT) due to stenosis of the inferior vena cava (IVC)-right atrial (RA) anastomosis. We also discuss the role of measuring femoral venous pressure and transesophageal echocardiography (TEE) in establishing the diagnosis.

Clinical features: A 42-yr-old female patient with idiopathic dilated cardiomyopathy underwent an $\mathrm{OHT}$, using the bicaval anastomotic technique. During the first $12 \mathrm{hr}$ postoperatively she developed unexplained kidney and liver failure. Her left and right ventricular functions were excellent and the right and left sided filling pressures were normal. The femoral pressure was elevated while the RA pressure was normal. An emergent TEE showed colour-flow and Doppler characteristics consistent with IVC-RA anastomotic stenosis. Emergent surgical re-exploration was undertaken; a hemostatic suture was found at the RA cannulation site that had caused the constriction of the IVC-RA anastomosis.

Conclusions: Acute liver and renal failure after $\mathrm{OHT}$ can have multiple causes including ischemia due to a low flow state. This case demonstrates the importance of doing a detailed intraoperative TEE after $\mathrm{OHT}$, and the importance of repeating the intraoperative examination after any hemostatic sutures are placed. Femoral venous pressure monitoring can be a useful diagnostic tool in detecting IVC-RA stenosis.
Objectif : Décrire l'occurrence d'insuffisance hépatique et rénale aiguës, survenant après une transplantation cardiaque orthotopique (TCO) bicave, causée par la sténose de l'anastomose entre la veine cave inférieure $(\mathrm{VCl})$ et l'oreillette droite (OD). Discuter aussi du rôle de la mesure de la pression veineuse fémorale et de l'échocardiographie transœsophagienne (ETO) dans l'établissement du diagnostic.

Éléments cliniques : Une femme de 42 ans, atteinte de cardiomyopathie dilatée, a subi une TCO selon la technique anastomotique bicave. Pendant les 12 premières heures postopératoires, une insuffisance rénale et hépatique inexpliquée s'est développée. La fonction des ventricules gauche et droit était excellente, les pressions de remplissage étaient normales des deux côtés. La pression fémorale était élevée, celle l'OD était normale. Un examen d'ETO d'urgence a montré des caractéristiques de débit chromatique et Doppler compatibles avec une sténose anastomotique VCI-OD. Une ré-exploration chirurgicale urgente a révélé la présence d'une suture hémostatique, au site de canulation de I'OD, causant la constriction de l'anastomose VCl-OD.

Conclusion : L'insuffisance hépatique et rénale aiguës suivant une TCO peut avoir de multiples causes dont l'ischémie provoquée par un bas débit. Le présent cas démontre l'importance de faire une ETO peropératoire détaillée après la TCO et de répéter cet examen après la mise en place de toute suture hémostatique. Le monitorage de la pression veineuse fémorale peut aider à détecter la sténose $\mathrm{VCl}-\mathrm{OD}$.

From the Departments of Anesthesiology and Surgery, ${ }^{*}$ and the Department of Anesthesiology, $†$ Washington University School of Medicine, St Louis, Missouri, USA.

Address correspondence to: Dr. Eric Jacobsohn, Washington University School of Medicine, Department of Anesthesiology, 660 S.

Euclid Ave - Campus Box 8054, St Louis, MO 63110, USA. Phone: 314-747-4155; Fax: 314-747-3977;

E-mail: jacobsoe@msnotes.wustl.edu

Accepted for publication March 2, 2006.

Revision accepted May 16, 2006.

Competing interests: None declared. 


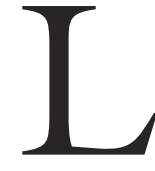

IVER dysfunction after orthotopic heart transplantation (OHT) is relatively common. ${ }^{1}$ It has multi-factorial causes, often including preexisting impaired hepatic perfusion due to the underlying cardiomyopathy. Liver dysfunction occurs more often if it is accompanied by hepatic congestion due to right heart failure, in combination with low cardiac output. ${ }^{2}$ Similarly, perioperative renal dysfunction is also common, and is multi-factorial in etiology, with reduced perfusion pressures and right heart failure being important factors. In the postoperative phase, right ventricular (RV) dysfunction is relatively common, and it is therefore not unusual to see deterioration in liver and renal function. However, these decreases are usually mild and improve rapidly as cardiac function improves. We report on a case of acute postoperative liver and renal failure after OHT in the presence of normal right and left ventricular (LV) function, and highlight the role of intraoperative transesophageal echocardiography (TEE) in establishing the diagnosis. Approval for this case report was obtained from the Washington University Human Studies Committee.

\section{Case report}

This case report describes a 42 -yr-old female patient who had a five-year history of progressive idiopathic dilated cardiomyopathy. Despite optimal medical management, which included digoxin, spironolactone, enalapril, coumadin and furosemide, she deteriorated to New York Association Class IV. She was added to the United Network for Organ Sharing (UNOS) waiting list for heart transplantation as a status II patient. A status II patient is defined as a patient who is homebound and requiring continuous medical care that can be self administered. Her pre-transplantation right heart catheterization revealed a reduced cardiac index (CI) and mildly elevated pulmonary vascular resistance, with a minor increase in the transpulmonary gradient. There was no evidence of preoperative liver or kidney impairment. The donor had died of a subarachnoid hemorrhage, and was not on any inotropic or vasopressor therapy. The donor's transthoracic echocardiogram (TTE) demonstrated normal left- and RV function.

Following induction of general anesthesia the following post-induction hemodynamics were recorded: pulmonary artery (PA) $39 / 24 \mathrm{mmHg}$, pulmonary capillary wedge pressure (PCWP) $19 \mathrm{mmHg}$, central venous pressure (CVP) $15 \mathrm{mmHg}$, CI 1.8 $\mathrm{L} \cdot \mathrm{min}^{-1} \cdot \mathrm{m}^{-2}$, mixed venous oxygen saturation $\left(\mathrm{SvO}_{2}\right)$ $62 \%$. The donor heart ischemic time was $160 \mathrm{~min}$. A bicaval anastomotic technique was used, and the

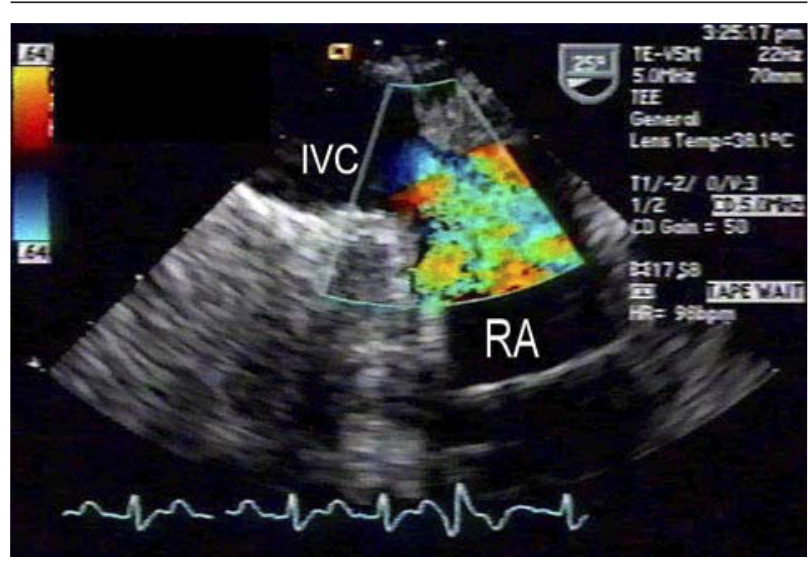

FIGURE la This shows the turbulent colour-flow Doppler at the junction of the IVC (inferior vena cava) and the RA (right atrium).

patient was separated from cardiopulmonary bypass $(\mathrm{CPB})$ while receiving dobutamine $5 \mu \mathrm{g} \cdot \mathrm{kg}^{-1} \cdot \mathrm{min}^{-1}$. Intermittent norepinephrine and vasopressin infusions were required to maintain the mean arterial pressure $>70 \mathrm{mmHg}$. The CVP, PA and PCWP pressures were low at all times $(5-11 \mathrm{mmHg}, 22 / 10-28 / 12 \mathrm{mmHg}$, $8-3 \mathrm{mmHg}$ respectively). The CI was $1.7-1.9 \mathrm{~L} \cdot \mathrm{min}^{-}$ ${ }^{1} \cdot \mathrm{m}^{-2}$, with $\mathrm{SvO}_{2}$ between $52-59 \%$. The post-CPB TEE showed excellent left- and RV function, normal valvular function, but an under-filled left ventricle. The patient was resuscitated with $5 \%$ albumin, and two units of packed red blood cells were transfused as the hematocrit was $24 \%$. However, the CI and $\mathrm{SvO}_{2}$ remained low. The subsequent course in the intensive care unit (ICU) revealed low right- and left-sided filling pressures (CVP 6-10 $\mathrm{mmHg}$, PCWP 9-12 $\mathrm{mmHg}$ ), a reduced $\mathrm{SvO}_{2}(55-61 \%)$ and CI (1.7-2.0 $\left.\mathrm{L} \cdot \mathrm{min}^{-1} \cdot \mathrm{m}^{-2}\right)$. An urgent TEE showed normal rightand left sided cardiac function, but a reduced LV enddiastolic volume. Over the course of the first three hours in the ICU, the patient became oliguric (urine output $<0.5 \mathrm{~mL} \cdot \mathrm{kg}^{-1} \cdot \mathrm{hr}^{-1}$ ). The oliguria persisted despite further volume loading with $5 \%$ albumin and transfusion of another two units of packed red cells; the post-transfusion hematocrit was $31 \%$. A complete metabolic profile done six hours after arrival in the ICU revealed severely elevated transaminases (AST 4900 international units (IU), ALT 4250 IU), an international normalized ratio (INR) of 2.1 , and a serum lactate of $4.9 \mathrm{mmol} \cdot \mathrm{L}^{-1}$.

The extensive differential diagnosis of acute liver failure after bicaval OHT was considered. In view of 


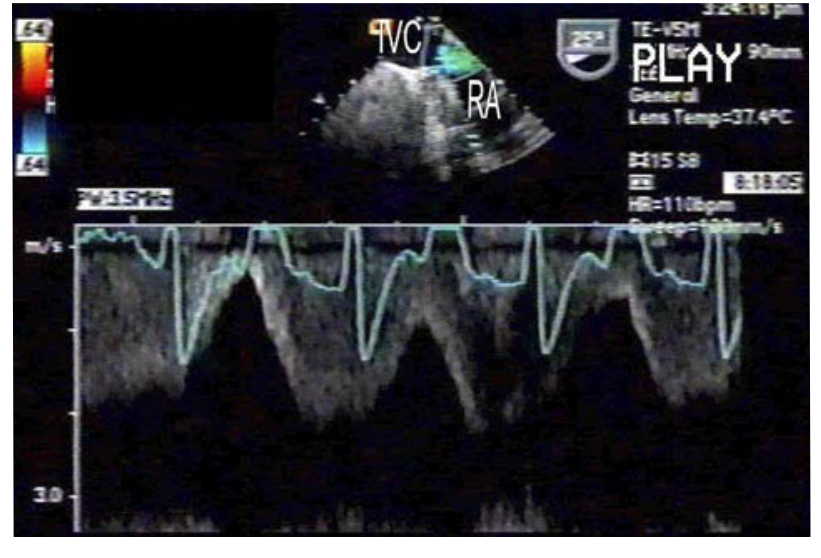

FIGURE lb Pulse-wave Doppler has been placed at the right atrium-inferior vena cava (RA-IVC) junction and shows a peak velocity (v) of approximately $2 \mathrm{~m} \cdot \mathrm{sec}^{-1}$. The gradient at the IVC-RA junction was calculated to be 16 $\mathrm{mmHg}$ using the modified Bernoulli equation (where the pressure gradient across a stenosis $=4 \mathrm{v}^{2}$ ). The RA pressure at the time of this transthoracic echocardiogram study was $12 \mathrm{mmHg}$ (from the RA port of the pulmonary artery catheter), making the IVC pressure approximately $28 \mathrm{mmHg}$.

the patient's normal preoperative liver function tests, good flows on $\mathrm{CPB}$, the lack of postoperative RV failure and only modestly reduced CI, the severely elevated transaminases were unexpected. Similarly, the onset of acute oliguria was also unexpected, as the patient had a normal preoperative blood urea nitrogen and creatinine, had not received any nephrotoxic drugs (such as calcineurin inhibitors), had a relatively short period on $\mathrm{CPB}$ with good perfusion pressures, and only a modestly reduced CI in the postoperative period. Therefore, as part of the differential diagnosis, the unifying diagnosis that could explain the clinical scenario was the possibility of an inferior vena cava (IVC) anastomotic site stenosis. We therefore transduced the femoral vein pressure from the distal lumen of a new pulmonary artery catheter (PAC) that was inserted into the femoral vein. The femoral vein pressure was $25 \mathrm{mmHg}$. We then gently advanced the catheter into the right atrium (RA). There was an acute drop in pressure as the PAC entered the right atrium (RA pressure $=12 \mathrm{mmHg}$ ). An emergency TEE showed colour-flow and Doppler characteristics consistent with an IVC anastomotic site stenosis (Figures la and lb; Video, available as Additional Material at www. cja-jca.org). Immediate re-exploration showed that a hemostatic suture at the cannulation site had caused constriction of the IVC lumen. Following surgi-

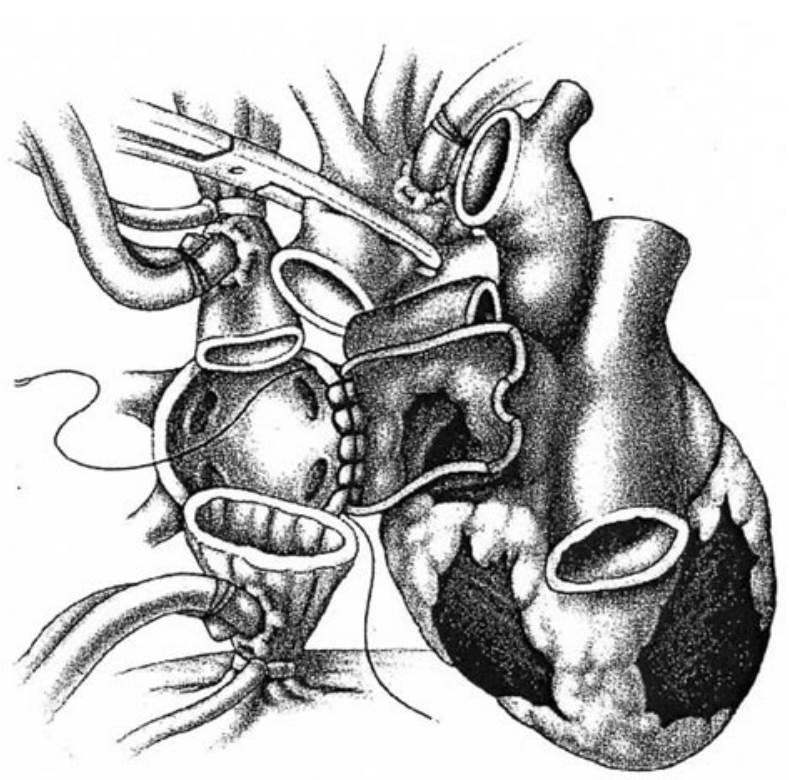

FIGURE 2a Commencement of left atrial anastomosis in the bicaval technique.

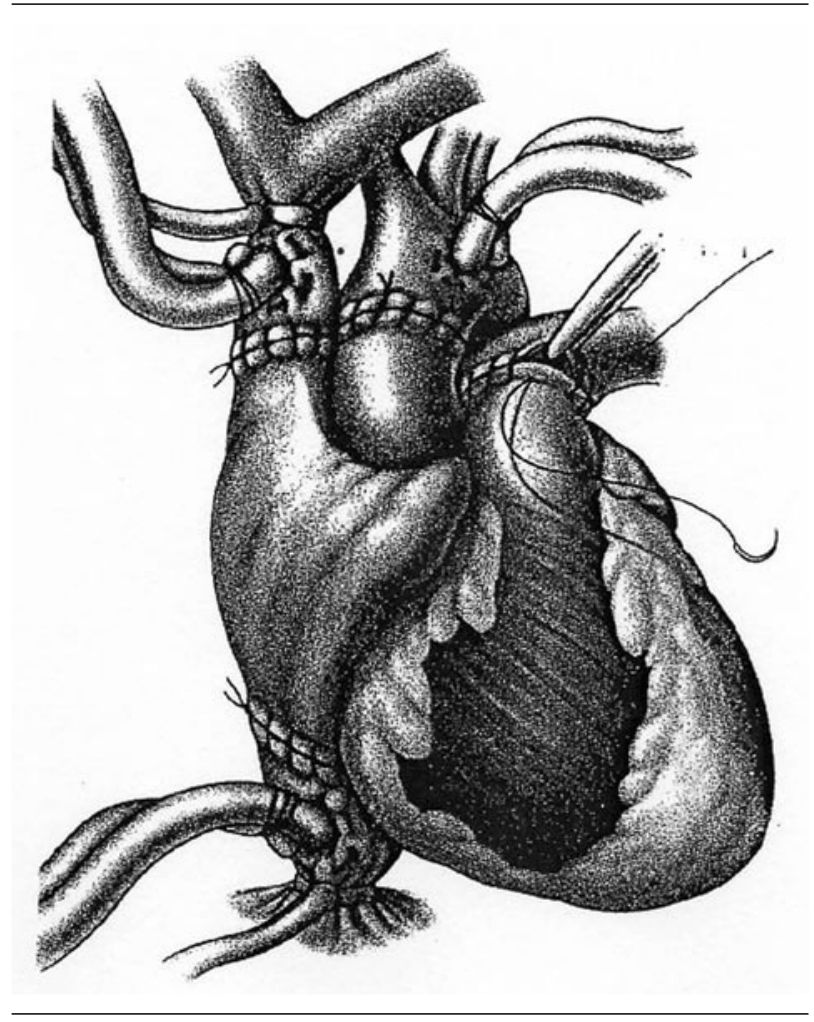

FIGURE $2 \mathrm{~b}$ Completion of bicaval transplant technique, showing the inferior vena caval, superior vena caval aortic, and pulmonary artery anastomoses. 


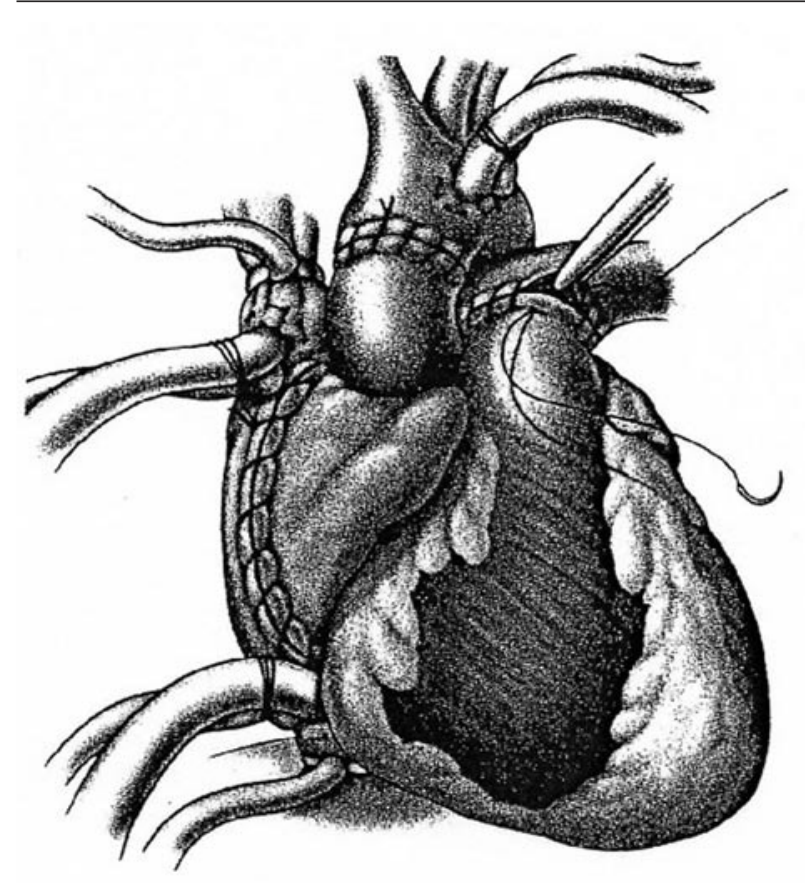

FIGURE 2c Completed biatrial orthotopic heart transplantation showing the aortic, pulmonary artery, and right atrial anastomoses. Figures $2 \mathrm{a}, \mathrm{b}$ and $\mathrm{c}$ reproduced with permission from Kirklin JK, Young JB, McGriffin DC. Heart Transplantation, $2^{\text {nd }}$ ed. Elsevier; 2005: 342.

cal repair, CI and $\mathrm{SvO}_{2}$ improved immediately and the oliguria resolved. The patient's serum creatinine peaked at $1.9 \mathrm{mg} \cdot \mathrm{dl}^{-1}$ on postoperative day one, and his serum transaminases and INR values returned to normal rapidly therafter.

\section{Discussion}

The bicaval anastomotic technique of OHT involves separate anastomosis of recipient IVC and superior vena cava (SVC) to the donor RA (Figures 2a, 2b). In the original, and still commonly used biatrial technique, a cuff of the recipient's RA with the attached IVC and SVC is anastomosed to the donor's RA (Figure 2c). The PA, aorta and left atrial anastomoses are the same in both techniques. The bicaval technique may offer certain advantages. These include improvement in post-transplant survival, better atrial geometry, improved hemodynamics, and a reduction in tricuspid regurgitation, early sinoatrial node dysfunction, arrhythmias, pacing, and vasopressor requirements, along with a reduced hospital stay. ${ }^{3-6}$ However, the IVC anastomosis can be difficult due to crowding of the surgical field by cannulae and tourniquets, ${ }^{7}$ and potential size mismatch. Similarly, the SVC anastamosis can be challenging, and the postoperative SVC syndrome is well described; however it is easily recognized by the appearance of a swollen upper body. ${ }^{8} 9$ Stenotic complications can also occur at the pulmonary artery and left atrial anastomotic sites.

Liver failure secondary to anastomotic IVC stenosis in OHT is exceedingly rare. ${ }^{10}$ Mild liver dysfunction is a common entity after heart transplantation, and the differential diagnosis includes preoperative liver dysfunction, low CI (especially in face of high RVIVC pressures), drug induced injury, and systemic infections. ${ }^{1,11}$ Unlike the SVC syndrome, the IVC-stenosis is less obvious clinically. This case illustrates the importance of considering the diagnosis after OHT, especially when cardiac function appears to be good and there is an unexplained degree of deterioration in liver (and renal) function. This case also highlights the importance of the anesthesiologist in performing a comprehensive intraoperative TEE examination after OHT, which should include a careful assessment of all the major anastomotic sites. The intraoperative TEE should be repeated after any additional hemostatic sutures are placed, as they can compromise a previously good anastomosis.

In summary, this case demonstrates the importance of a detailed intraoperative TEE after OHT, and the importance of repeating the intraoperative examination after any hemostatic sutures. We also highlight the crucial role which the anesthesiologist/intensivist assumed in the early diagnosis of this serious complication.

\section{References}

1 Dichtl W, Vogel W, Dunst KM, et al. Cardiac hepatopathy before and after heart transplantation. Transpl Int 2005; 18: 697-702.

2 Raman JS, Kochi K, Morimatsu H, Buxton B, Bellomo $R$. Severe ischemic early liver injury after cardiac surgery. Ann Thorac Surg 2002; 74: 1601-6.

3 Morgan JA, Edwards NM. Orthotopic cardiac transplantation: comparison of outcome using biatrial, bicaval, and total techniques. J Card Surg 2005; 20 : 102-6.

4 Magliato KE, Trento A. Heart transplantation-surgical results. Review. Heart Fail Rev 2001; 6: 213-9.

5 Traversi E, Pozzoli M, Grande A, et al. The bicaval anastomosis technique for orthotopic heart transplantation yields better atrial function than the standard technique: an echocardiographic automatic boundary detection study. J Heart Lung Transplant 1998; 17: 1065-74. 
6 Trento A, Takkenberg JM, Czer LS, et al. Clinical experience with one hundred consecutive patients undergoing orthotopic heart transplantation with bicaval and pulmonary venous anastomoses. J Thorac Cardiovasc Surg 1996; 112: 1496-1503.

7 Aklog L, Sepic J, Filsoufi F, Byrbe JG, Adams DH. Open inferior vena caval anastomosis during bicaval heart transplantation. Ann Thorac Surg 2002; 73: 671-2.

8 Sze DY, Robbins RC, Semba CP, Razavi MK, Dake $M D$. Superior vena cava syndrome after heart transplantation: percutaneous treatment of a complication of bicaval anastomoses. J Thorac Cardiovasc Surg 1998; 116: 253-61.

9 Blanche C, Tsai TP, Czer LS, Valenza M, Aleksic I, Trento $A$. Superior vena cava stenosis after orthotopic heart transplantation: complication of an alternative surgical technique. Cardiovasc Surg 1995; 3: 549-52.

10 Bleasdale RA, Partridge J, Banner NR. Obstruction of the inferior vena cava following total heart lung transplantation: successful treatment by balloon angioplasty. J Heart Lung Transplant 2000; 19: 488-91.

11 Andrade RJ, Lucena MI, Fernandez MC, et al.; Spanish Group for the Study of Drug-Induced Liver Disease. Drug-induced liver injury: an analysis of 461 incidences submitted to the Spanish registry over a 10-year period. Gastroenterology 2005; 129: 512-21. 